\title{
DOS ESTELAS EN LA MIXTECA BAJA DEL SUR DE PUEBLA
}

\author{
Hasso von Winning \\ Southwest Museum \\ Las Angeles, Calif.
}

En el sector de la Mixteca Baja, que se extiende por el sur de Puebla y el noroeste de Oaxaca, se han localizado esculturas de piedra con inscripciones jeroglíficas en un estilo regional que Paddock (1965) denomina Nuiñe, palabra mixteca que significa "tierra caliente". Hasta la fecha se han encontrado unos cincuenta monumentos esculpidos y diez urnas de cerámica parecidas a las urnas zapotecas. El estilo floreció en la segunda mitad del clásico medio, ca. 550-700 d.C., y se compone de elementos iconográficos derivados del arte de Teotihuacan, de Veracruz y de Oaxaca. Moser (1977) publicó un catálogo de los monumentos y de los signos iconográficos e identificó varios glifos calendáricos correspondientes al sistema mesoamericano, y otros que probablemente se refieren a lugares o nombres personales. También incluyó un mapa de la extensión aproximada del estilo Nuiñe (figura 7) .

Aunque las dos estelas, objeto del presente estudio, se encuentran

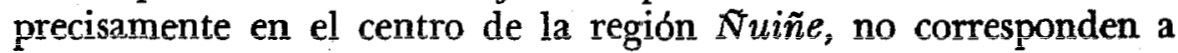
este estilo porque incluyen escasos elementos, de los identificados por Moser, y además contrastan por su complejidad con las características que él describe como ". . . un estilo poco dinámico, con espacios abiertos, y limitado en su contenido narrativo ... además, ocurren raras veces las figuras humanas" (p. 189). Por lo tanto, las dos estelas son de un periodo posterior y pertenecen al epiclásico.

Ambas estelas fueron esculpidas de piedra esquistosa con gruesas venas de cuarzo, extraída del caudal del Río Mixteco, a poca distancia de Guadalupe Santa Ana, al suroeste de Acatlán. Uno de los monumentos, la Estela de Guadalupe, todavía se encuentra cerca de la cantera, el otro fue trasladado a la plaza del pueblo El Rosario Micaltepec, a unos $40 \mathrm{~km}$ al este.

\section{La Estela de Micaltepec}

Se han publicado dos pequeñas fotografías en el Catálogo arqueológico y etnohistórico de Puebla-T Taxcala, compilado por P. Tschohl 
(vol. 2, 1977, 469, 480). Durante mi visita a Micaltepec, en enero 13-14, 1979, me informaron que la estela había sido encontrada al pie del Cerro de la Laguna, a unos 4 o $5 \mathrm{kms}$ del pueblo. En la cima del cerro se notan restos de muros prehispánicos y cerca del lugar donde se había sacado la estela existen montículos con restos de piedras revestidas con estuco. En 1962 se intentaba empotrar la estela en la fachada de la iglesia, pero dándose cuenta que está esculpida en los dos lados, se optó por erigir una pequeña torre que a la vez se utiliza para izar la bandera nacional. Resulta que los lados angostos de la estela, quedan cubiertos por los muros de la torre, oscureciendo también parte de los márgenes. Ahora un lado de la estela da al oeste, el otro al este. El monumento está tallado en bajorrelieve; por las grietas, las intrusiones de cuarzo y los efectos del tiempo, la superficie es irregular y algunos detalles están destruidos (figuras 1 y 3 ).

En la cara del lado oeste se reconocen dos configuraciones humanas, de medio cuerpo, una encima de la otra (figura 2). La figura superior es frontal y sostiene en las manos plantas de maíz. La figura inferior está de perfil, tiene el mismo tamaño y extiende las manos. Debajo de cada una de las caras se nota un motivo de la iconografía teotihuacana en forma de " $U$ " con volutas laterales, que corresponden al corte transversal de una vasija y contiene un glifo en su cartucho.

Junto al glifo de la deidad del maíz hay tres círculos y dos barras en un arreglo semejante al de la placa de tecali de Ixtapaluca (figura 4), en la cual la diosa del maíz aparece con su nombre "7 ojo de reptil". En Micaltepec no se puede determinar el sexo de la deidad, porque solamente se representa la parte superior de la figura. El glifo se asemeja a una concha bivalva estilo teotihuacano, y tiene cinco líneas verticales (figura 5, a). Debajo del glifo "concha" están colocados simétricamente tres círculos que son relativamente pequeños en relación con las dos barras, que por su parte se extienden más hacia la derecha. Por eso la inscripción puede leerse "3. 'concha"” o "13. 'concha" ". En la Mixteca Baja se acostumbraba, durante todo el periodo clásico, poner los círculos "encima" de las barras, mientras que el orden fue invertido en el periodo III-A en Monte Albán, de modo que los círculos se colocaron "abajo" de las barras. 
Entre los signos de los días en el sistema $\tilde{N} u i \tilde{n} e$ se destacan dos que tienen semejanza con el glifo "concha", siendo el del $12^{\circ}$ día "hierba" (malinalli, figura 3, b) y el 13ㅇ día "caña" (acatl, figura 3,c). Llama también la atención el elemento ovalado (una cuerda doblada) unida al cartucho "concha" (figura 3, a). Alfonso Caso (1967: 179, figura 17) e independientemente H. B. Nicholson (1966: 135, 140, figura 2) han demostrado que la cuerda doblada identifica el glifo acompañante como un portador de año en monumentos del fin del clásico o principios del posclásico, en Xochicalco, la Mixteca Alta y en Veracruz. Cuando terminó el clásico tardío se cambió de posición a los portadores de año, moviéndoles del $2^{\circ}$ día (viento), $7^{\circ}$ día (venado), $12^{\circ}$ día (hierba) y $17^{\circ}$ día (movimiento) a la posición que sigue, o sea al $3^{\text {er }}$ día (casa), $8^{\circ}$ día (conejo), $13^{\circ}$ día (caña) y $18^{\circ}$ (pedernal). Por consiguiente, la fecha en cuestión sería "año 13. caña". Thompson (1950; 81-82) anotó que el día maya ben, que corresponde al día acatl (caña), probablemente representa una planta de maíz brotando.

En resumen, es plausible que la mitad superior de la Estela de Micaltepec oeste representa la celebración del nacimiento del maíz, o sea el tema que se expresa también en la Estela 3 de Xochicalco (Pasztory 1973: 188).

En la mitad inferior de la estela se halla una cabeza de perfil, con tocado en forma de una gran mandíbula, con el pico enrollado como en las fauces celestiales de los monumentos zapotecos. Arriba se encuentra una " $U$ " invertida con dos volutas en los lados, que corresponde al signo 25 del Catálogo de Moser. Pero el elemento ocurre solamente una vez en el arte Nuiñe; lo encontramos en la Estela 3 de Xochicalco (D-13) y frecuentemente como glifo maya T-125 (=ah, prefijo reverencial). La vírgula de la palabra, la boca con sus dientes grandes y el gesto elocuente (con dos granos de maíz encima de una mano?) son los atributos de los dioses de la fertilidad vegetal en Teotihuacan, en la Estela 1 de Xochicalco (Pasztory 1973:189) y también de un gran número de deidades posclásicas de la vegetación (Nicholson 1964:22).

Debajo de los brazos el corte transversal de la vasija contiene un glifo desconocido. Está protegido por el borde realzado del cartucho y muy bien conservado. Los dos círculos (numeral 2) se encuentran "dentro" del cartucho, no abajo de él, lo que indica que el 
glifo no es calendárico sino que significa un nombre personal o un toponímico de un lugar terrestre o celestial (Caso 1967:182) .

En resumen, las dos imágenes del lado oeste de la Estela de Micaltepec representan aspectos rituales de deidades del maíz joven o naciente; con sus nombres y fechas.

La mayor parte del lado opuesto (Micaltepec este) está ocupada por signos calendáricos, tal como sucede en las tres estelas de Xochicalco, en las cuales un lado tiene figuras de deidades, el otro glifos del calendario. El gran símbolo del año se compone de un trapecio con una " $\mathrm{A}$ " (figura 3), como en el signo del año de la Lápida del Museo Pigorini (figura 6), cuyo origen no se conoce. Muy probablemente también es de la Mixteca Baja y poterior al estilo Nuiñe. Moser la incluyó en su lista de los símbolos del año, aunque solamente se conocen cuatro monumentos Nuiñe con un signo del año.

La barra con tres elementos ovalados debajo del signo, en $\mathrm{Mi}$. caltepec este, es un motivo abreviado del bulto atado que también ocurre en la Lápida Pigorini y en la Estela de Guadalupe. Sigue un glifo en cartucho cuyo significado es desconocido $\mathrm{y}$, más abajo, el numeral 13. Tiene los ćŕculos "abajo" de las barras, mientras que en todas las inscripciones $\tilde{N} u i \tilde{n} e$, con una sola excepción, los círculos o puntos están "encima" de las barras. Las líneas diagonales en las barras tienen la misma dirección como las de las tres estelas de Xochicalco.

En la base del monumento hay una gran cabeza de un felino, tal vez un jaguar que representa la tierra.

Concluimos que el lado este da la fecha, "Año 13. ??", en que se celebraron, al fin de un ciclo (?) las fiestas en honor de las deidades de la vegetación esculpidas en el lado opuesto.

\section{Estela de Guadalupe (figuras 8, 9 y 10)}

Afortunadamente fue posible reunir algunos datos interesantes e inéditos acerca de este monumento. Caso publicó un breve comentario sobre los motivos esculpidos, basándose en dos fotografías tomadas en 1953 por el doctor Erardo Weihmann, quien reside en la ciudad de México: 
En el lado frontal de la estela está esculpido el símbolo del año mixteco con una casa con techo de paja sobre una plataforma doble. Debajo parece que hay dos barras y uno o tres puntos, lo que significaría "Año 11. o 13. Casa". Al otro lado de la piedra se ve una piel de jaguar atravesada por una flecha con un numeral 1 , tal vez sea el día "1. caña" (Caso 1965:860-861; traducción del autor).

En vista de la importancia iconográfica del monumento, el señor Weihmann me proporcionó numerosas fotografías amplificadas del monumento y sus alrededores, así como un reporte detallado de su visita, en mayo de 1953. Iba acompañado por un ingeniero de la Secretaría de Recursos Hidráulicos, ahora fallecido, quien estuvo encargado de trabajos hidráulicos en esta región semiárida, y por sus esfuerzos ganó la amistad de los campesinos. Algunos de ellos, guiados por un cazador de venados, condujeron a los visitantes al sitio de la estela en una caminata de varias horas. Junto a la estela se encuentran estructuras de mampostería con muros estucados que habían sido saqueadas extensivamente, lo que explica por qué los vecinos de Santa Ana Guadalupe no quisieron proporcionar informaciones sobre su ubicación (figuras 11 y 12).

Encima del monumento se encuentra un canto rodado con restos vegetales entremetidos y en el lado del jaguar hay una plataforma (altar?), que consiste de una gran losa de piedra sobre piedras sueltas. Es obvio que por lo menos hasta mayo de 1953, la estela estuvo de pie y seguía siendo venerada.

En el lado del altar está esculpido un jaguar postrado, con la cabeza hacia abajo y con las cuatro patas extendidas (figura 8). Entre las patas posteriores se ve una placa cuadrangular en forma de un gran cartucho con el numeral 1, y de ér se proyecta el astil de una lanza o dardo. Culmina en tres elementos con un círculo, lo que Caso interpretó como la fecha "l. acatl (caña)". El astil del dardo penetra el cuerpo del tigre y la punta emerge de las fauces. Los ojos y las orejas están extendidas en ambos lados. Aunque faltan las manchas típicas de jaguar, no cabe duda que se trata de un tigre.

En el frente el monumento está aplanado, los lados y la cara posterior aproximan la forma de una columna redondeada y muestran el símbolo del año con un bulto atado, así como numerales parcialmente destruidos. La unión del símbolo del año y el bulto atado indican la terminación de un ciclo de 52 años. 
Un jaguar atravesado por una flecha evoca los pasajes sobre los augurios en los códices Borgia, Cospi y Vaticano $B$, que trata de la primera aparición del planeta Venus como estrella matutina, después de su conjunción inferior (Seler 1902:GA2:618-667). En cinco escenas sucesivas la estrella matutina, en su aspecto humano de Tlahuizcalpantecutli, arroja una flecha (es decir, los rayos mortíferos) contra varias deidades y objetos rituales. Entre las víctimas que nos interesan aquí, se encuentran Tezcatlipoca (Borgia 54), representado por un jaguar (Vaticano $B 84$ y Cospi 11), y un trono cubierto de piel de jaguar, símbolo del gobernante (Borgia 54, Vaticano $B$ 83, Cospi 10). En aquellas escenas Tlahuizcalpantecutli es victorioso y amenaza la humanidad con enfermedades y castigo divino.

Ofrecemos dos alternativas para explicar el significado de la piel de tigre con el dardo en el monumento, tomando en cuenta que el culto del planeta Venus tuvo supremacía en la región de Tlaxcala, Puebla y el norte de Oaxaca, y que la estela está situada precisamente en la región limítrofe de Puebla y Oaxaca.

1. Asumiendo que el monumento intenta conmemorar un episodio histórico, la piel con la flecha simbolizaría la derrota de un gobernante y la conquista de su capital provincial en la fecha grabada en el otro lado de la estela, en un "año 11. o 13. casa", según Caso. Tal acontecimiento puede relacionarse con las guerras que los mixtecos condujeron después de haberse establecido en Tilantongo (720, d. C. ?) y que culminaron con la conquista de Cholula (ca. 792 d. C.) Según Jiménez Moreno (1966: 62) Cholula fue conquistada por los olmecas históricos, un grupo triétnico compuesto de nahuas, mixtecos y chochopopolocas. El hecho que los mixtecos eran grandes artífices lapidarios y, al mismo tiempo, muy dedicados a registrar sus proezas en esculturas y pinturas, sugiere que dichas cualidades los motivaron para expresar simbólicamente un episodio de su historia en la estela. Fueron gentes del mismo grupo triétnico quienes pintaron las escenas guerreras en los murales de Cacaxtla, cuya fecha es aproximadamente 750-800 d. C. (información verbal de Marta Foncerrada de Míolina).

2. Una explicación mitológica es también plausible. Caso observó (1965: 861) que la fecha "1. caña" está grabada arriba, junto a la lanza, y una comparación de varias fotografías que se me han 


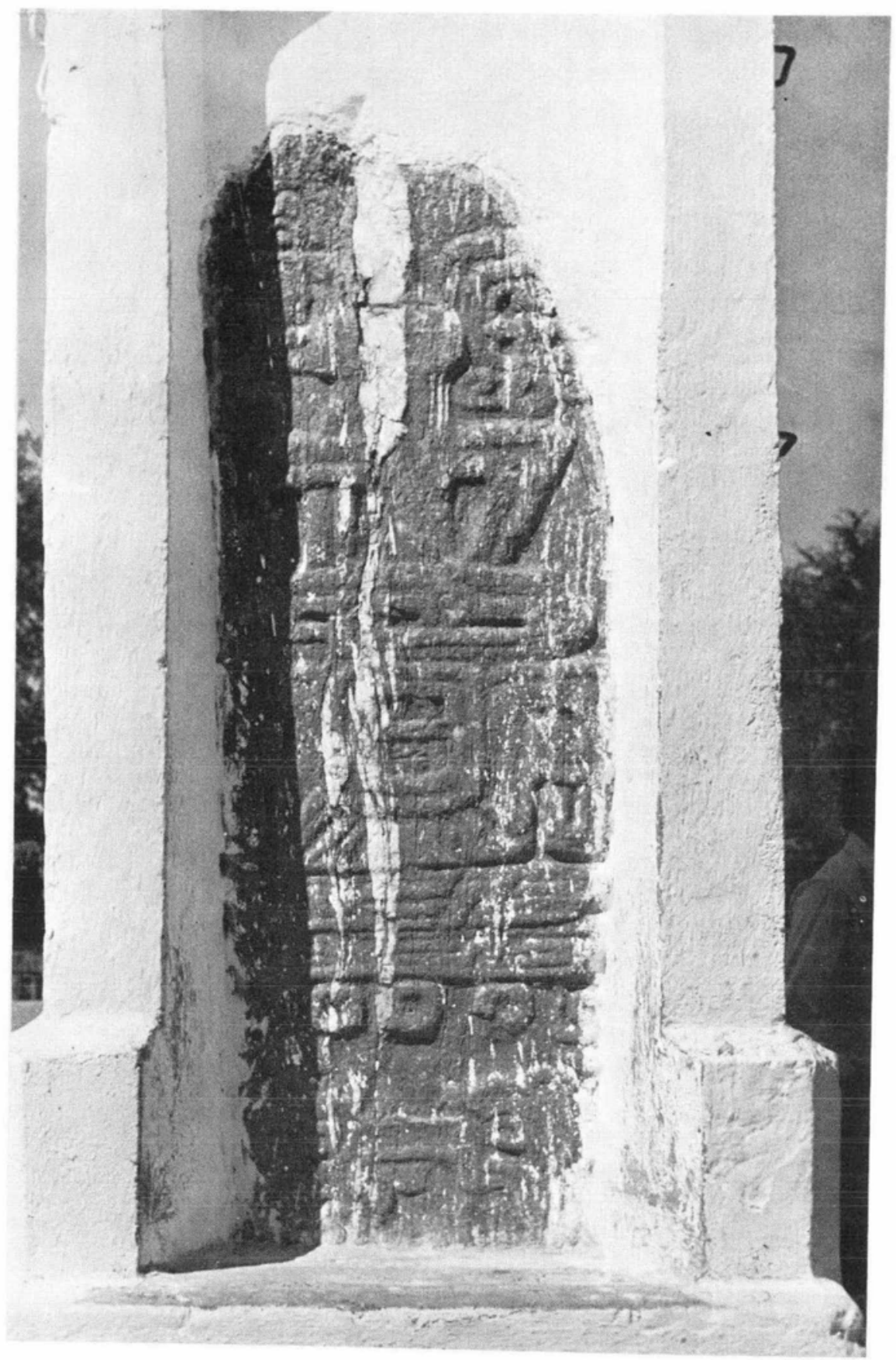

Figura 1. Estela en la plaza de El Rosario Micaltepec, Puebla. Altura 145 cm; 35 de grueso. Lado este. Fotografía de HvW, enero 14 de 1979. 
DOI: http://dx.doi.org/10.22201/iie.18703062e.1979.49.1123

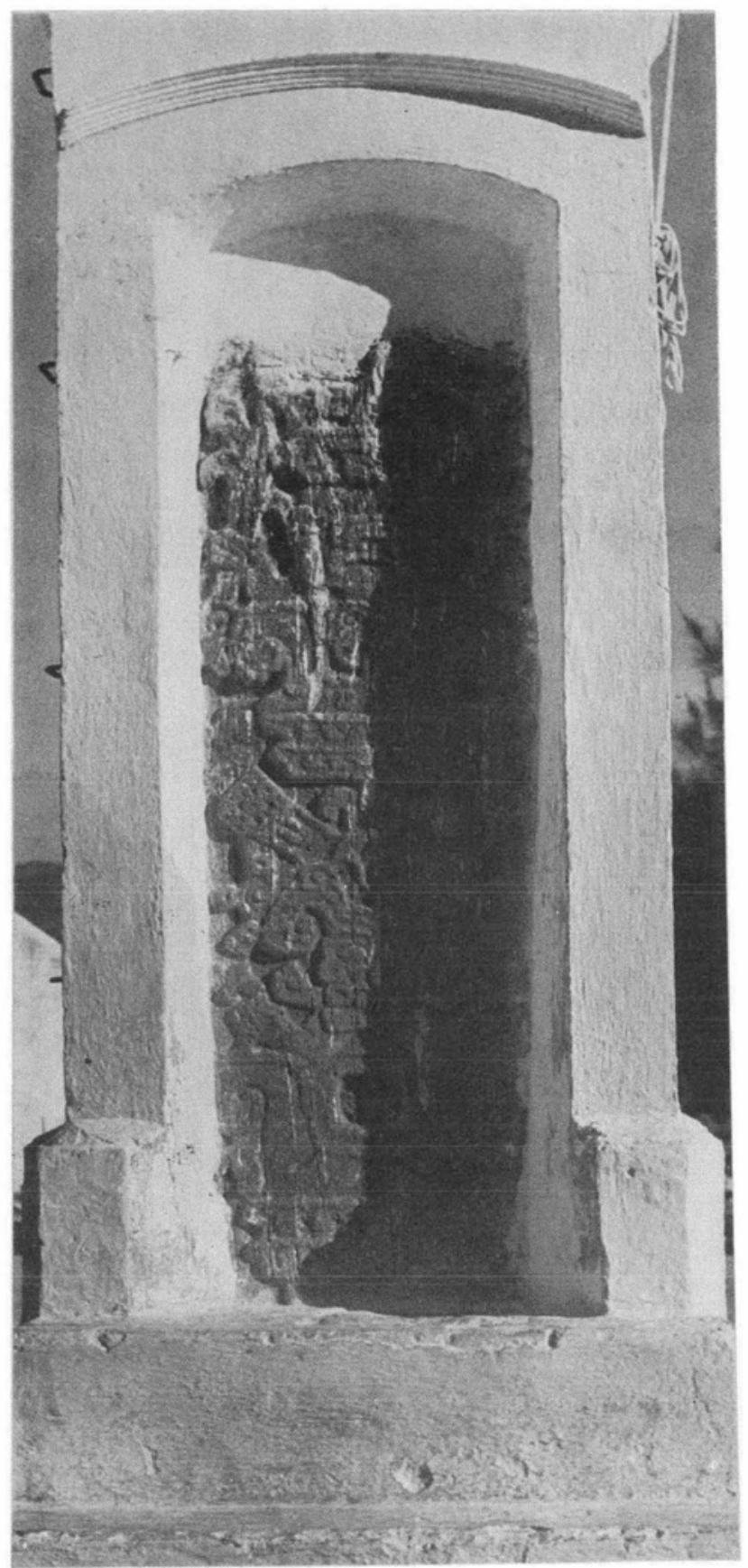

Figura 2. Estela en la plaza de El Rosario. Lado oeste. Fotografía de HvW, enero 13 de 1979. 

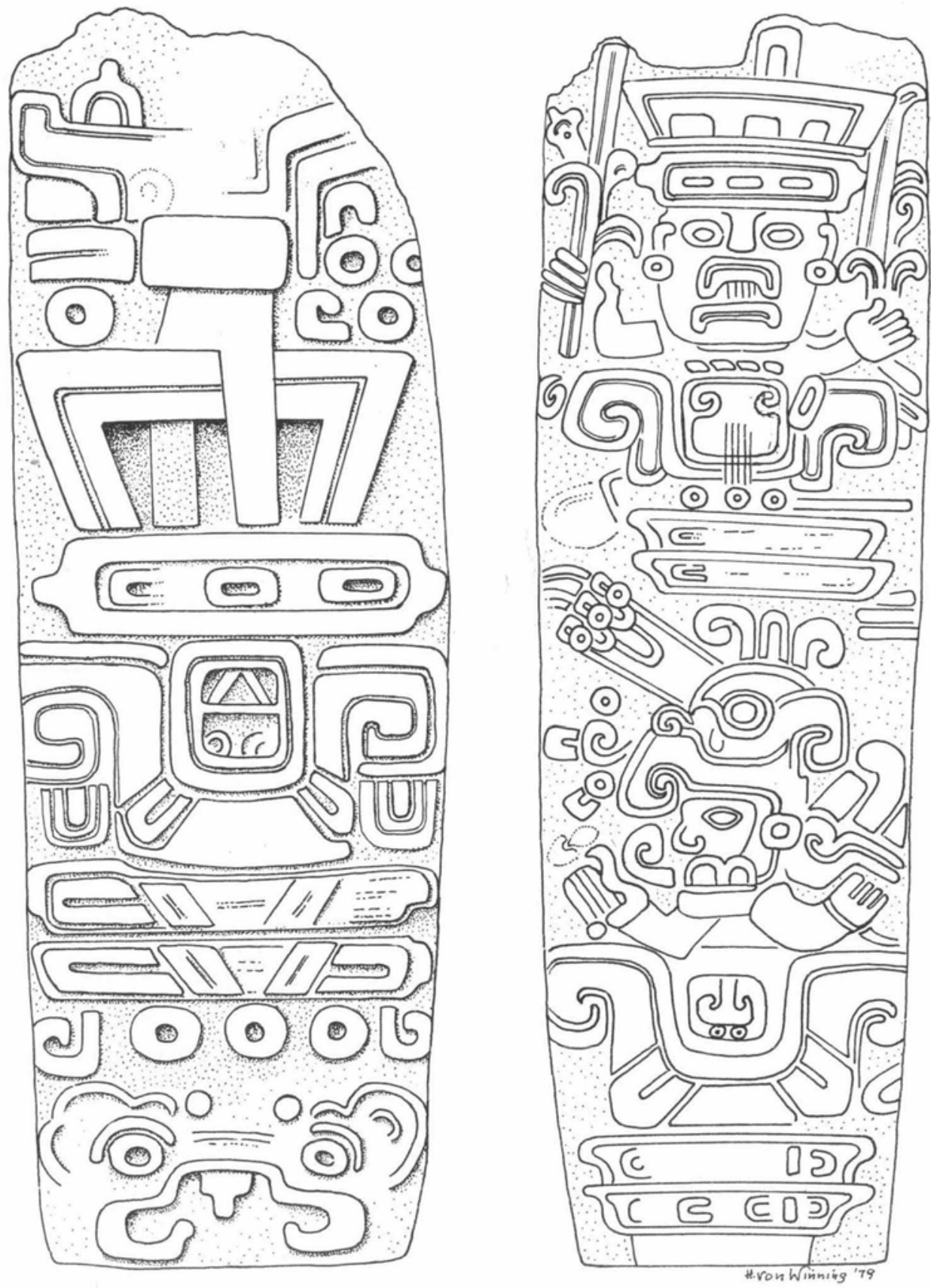

Figura 3. Estela de Micaltepec. Lado este (izquierda), lado oeste (derecha). Dibujo de HvW. 


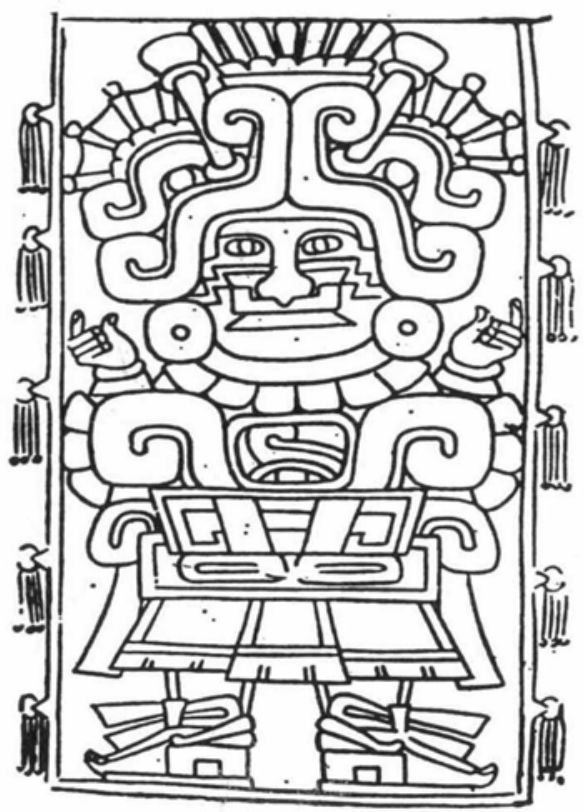

Figura 4. Pla $\ell$ de Tecali de Ixtapaluca (Chalco), según Caso, 1967, p. 158, figura 12 .
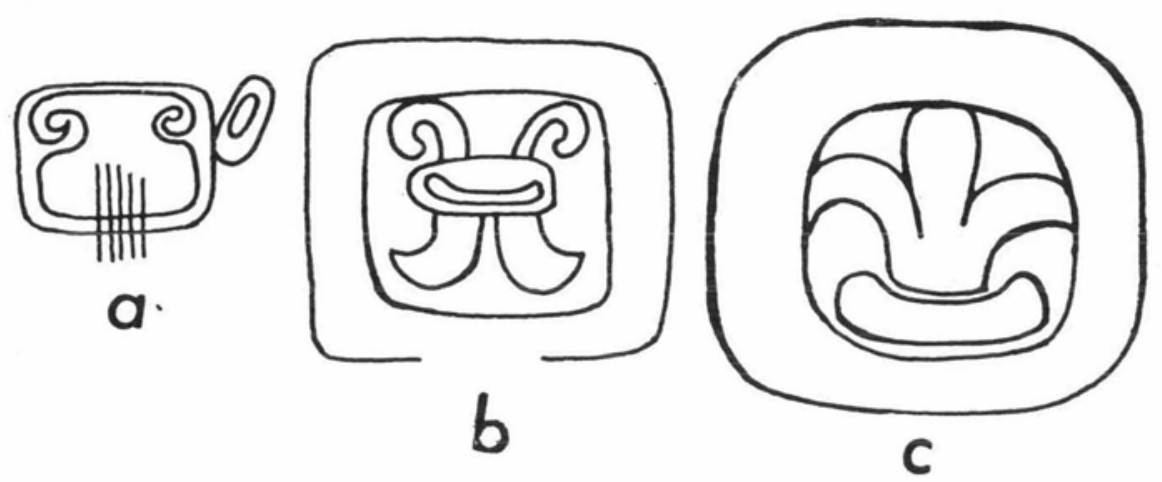

Figura 5. A-Glifo "Concha", Micaltepec Oeste. B-Signo del día correspondiente al Glifo "Hierba" en los monumentos Ñuiñe, según Moser 1977, p. 123 y 168, figura 52. C-Signo del día-caña, según Moser 1977, página 129, signo 61 . 

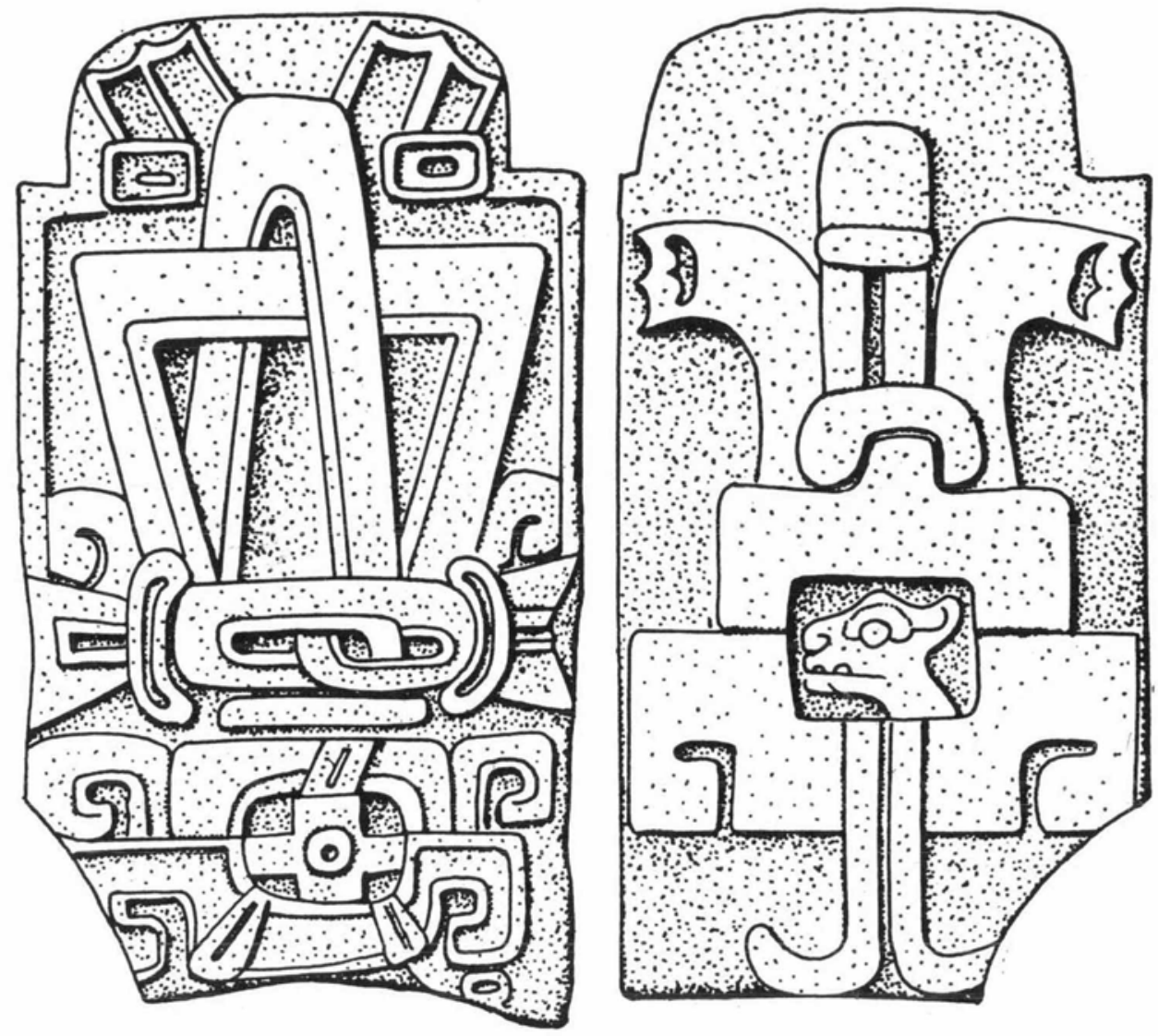

Figura 6. Lápida del Museo Pigorini, Roma. Frente (dibujo enmendado) y reverso, según Moser 1977, figura 63. 
DOI: http://dx.doi.org/10.22201/iie.18703062e.1979.49.1123

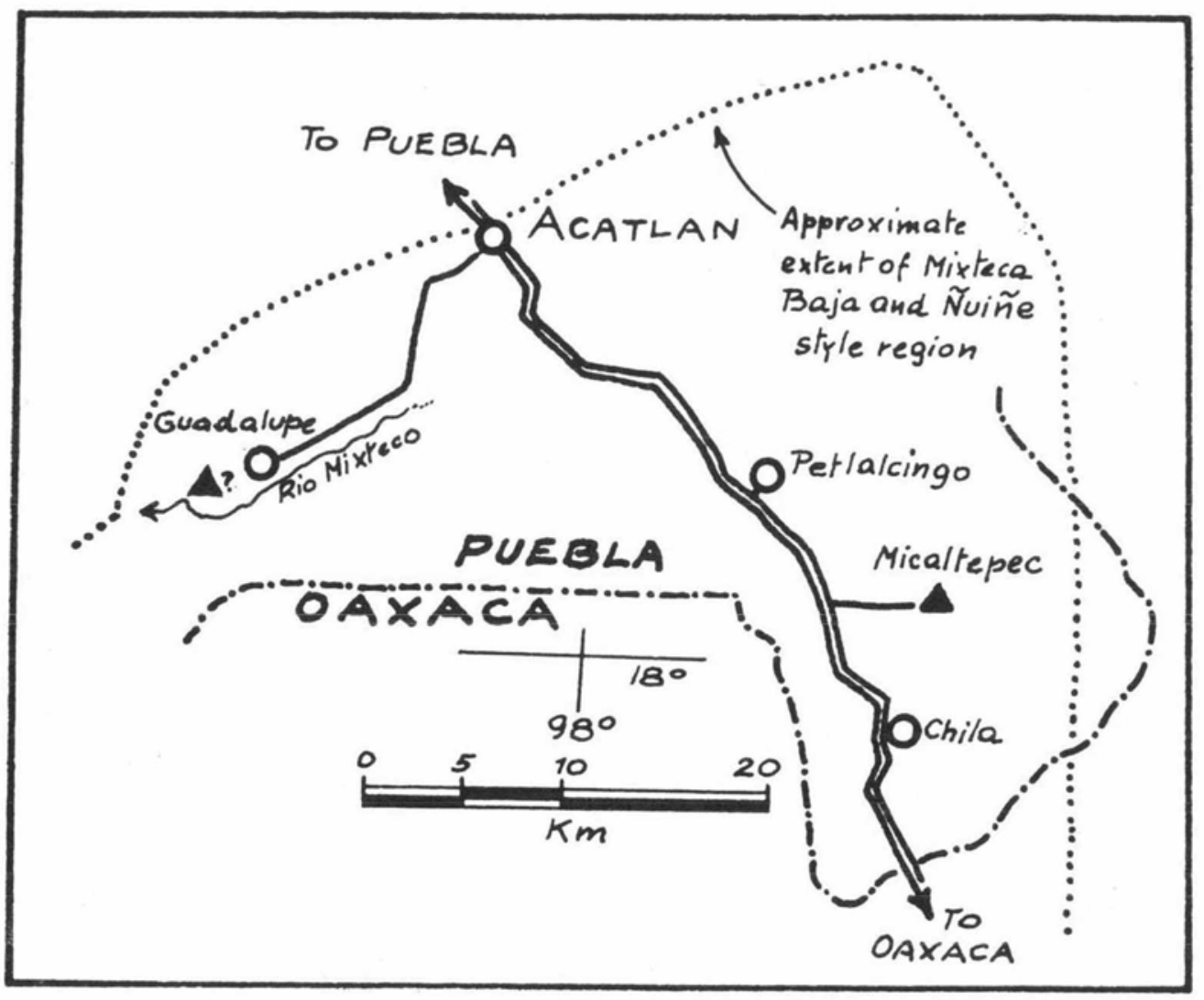

Figura 7. Mapa de la Región Nuiñe en la Mixteca Baja. 


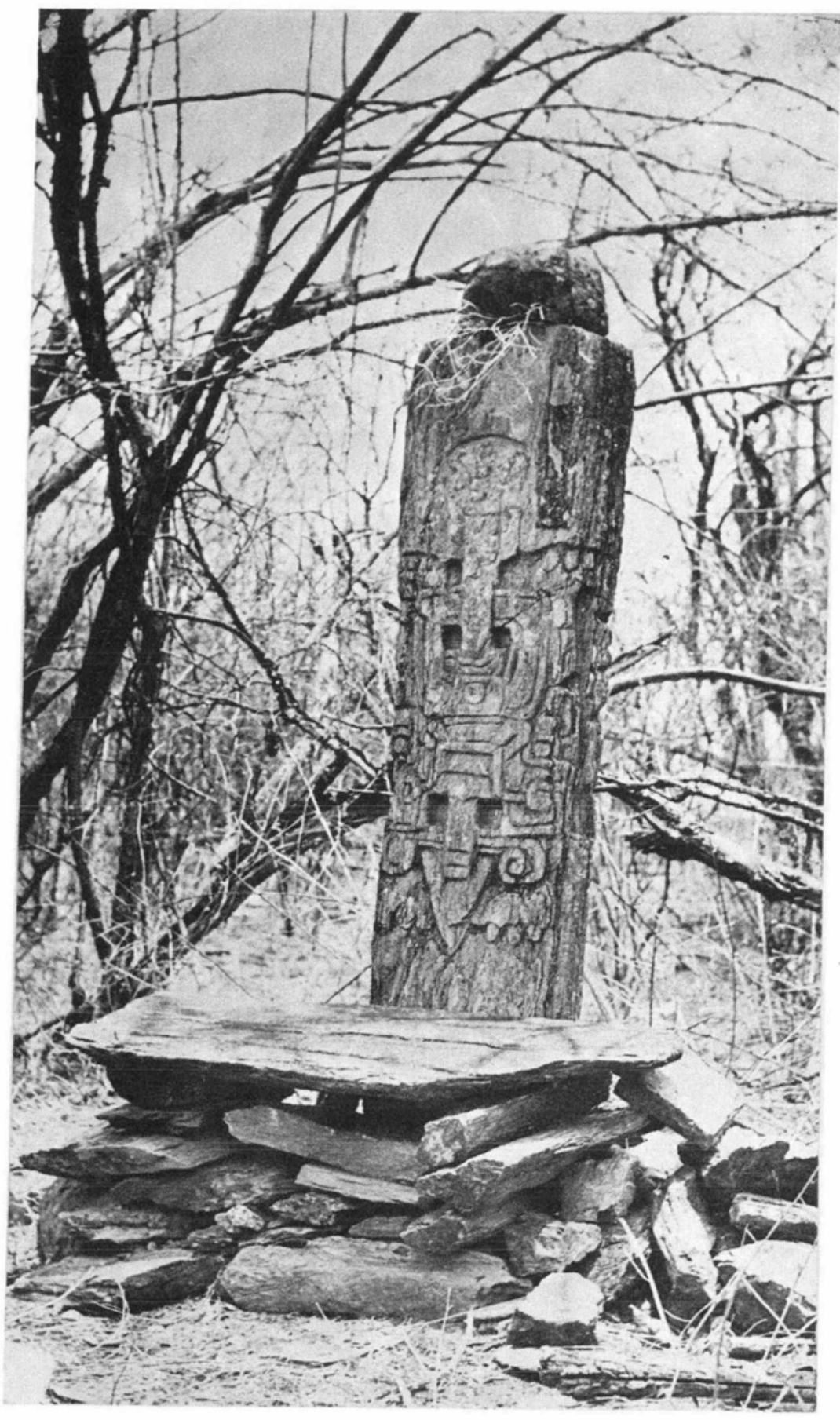

Figura 8. Estela de Guadalupe, frente. Altura aproximada $170 \mathrm{~cm}$. Fotografía de E. Weihmann, mayo de 1953. 


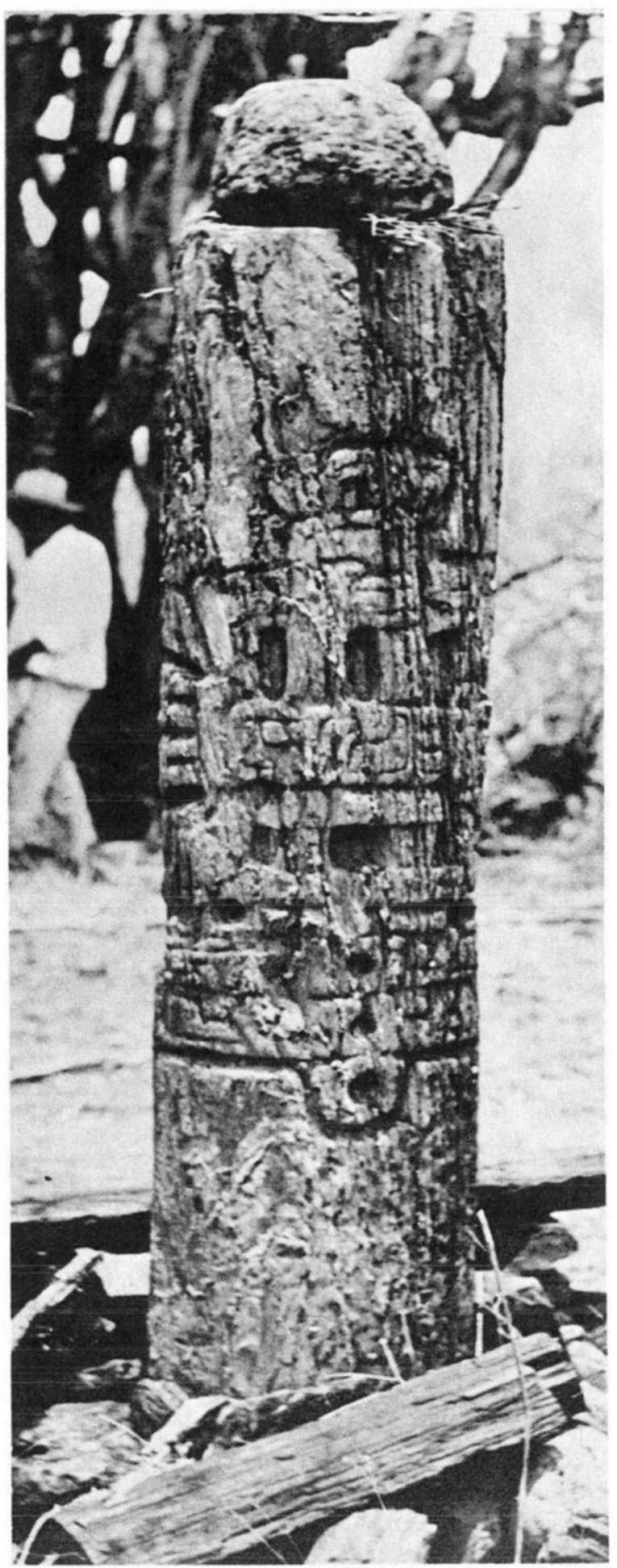

Figura 9. Fstela de Guadalupe, reverso. Foto E. Weihmann, mayo de 1953. 


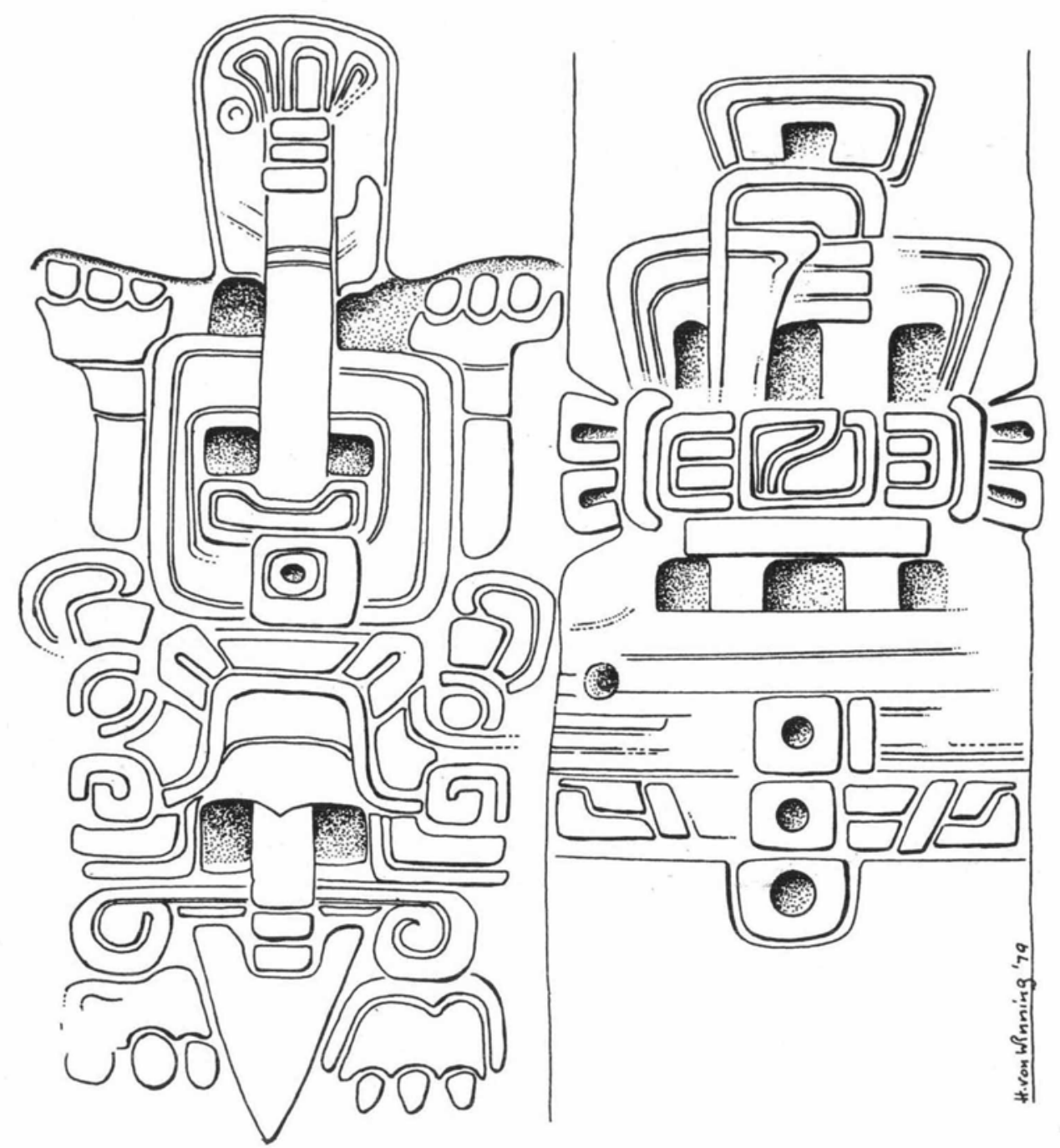

Figura 10. Dibujo de la estela de Guadalupe. Según fotografía de E. Weihmann, mayo de 1953. 


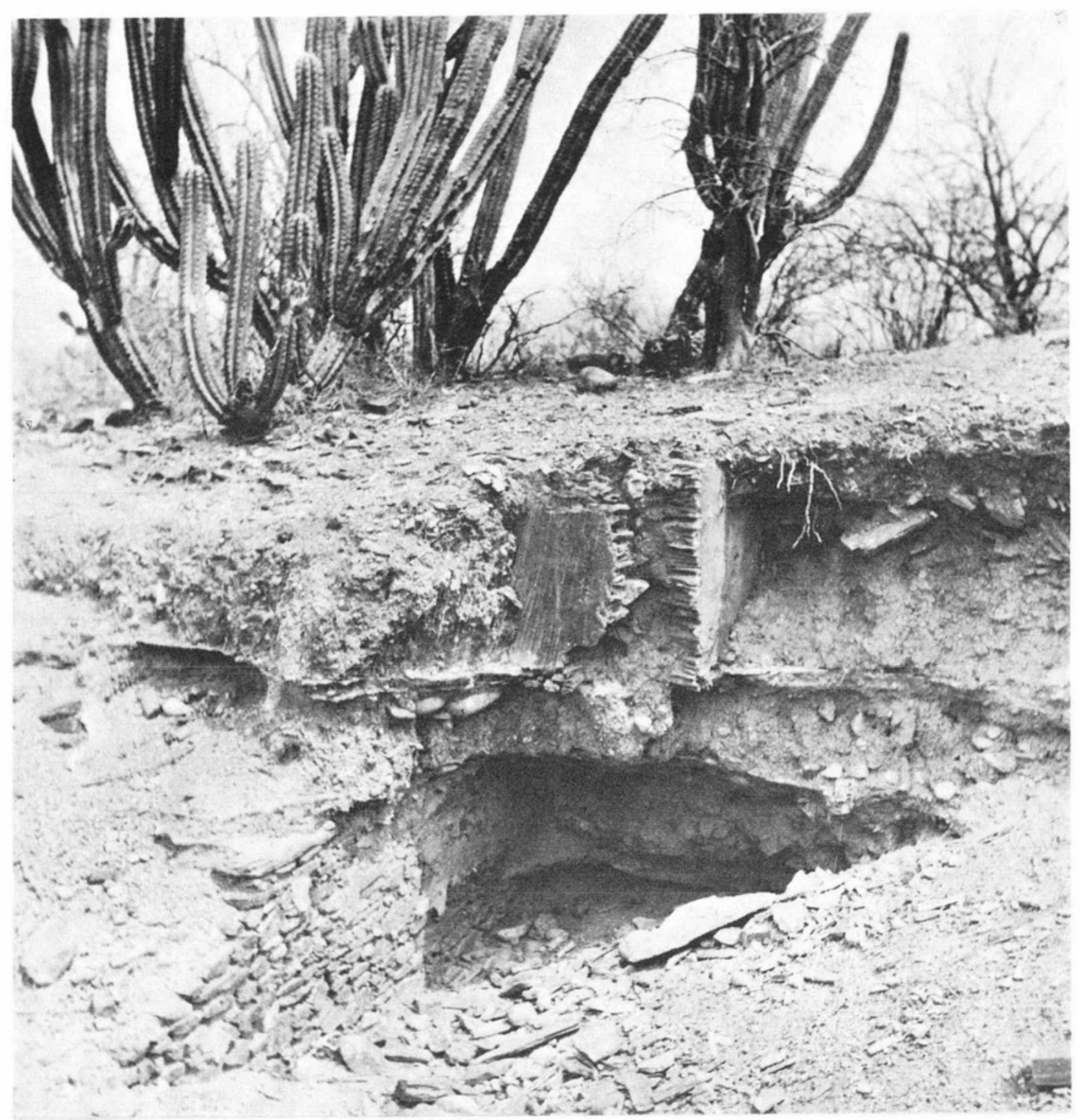

Figura 11. Estructuras saqueadas junto a la estela de Guadalupe. Fotografías E. Weihmann, mayo de 1953. 
DOI: http://dx.doi.org/10.22201/iie.18703062e.1979.49.1123

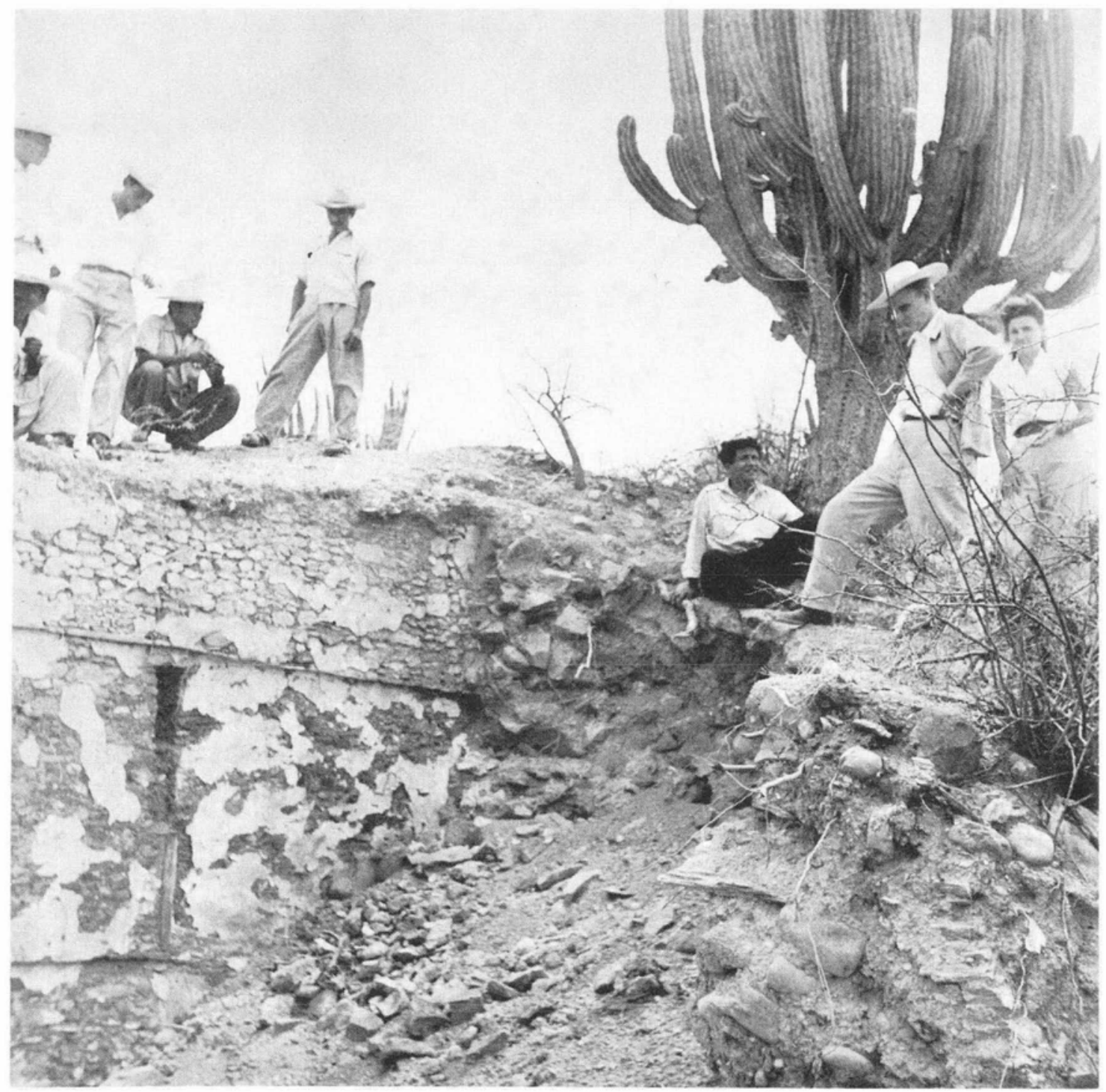

Figura 12. Estructuras saqueadas junto a la estela de Guadalupe. Fotografía de Weihmann, mayo de 1953. 
DOI: http://dx.doi.org/10.22201/iie.18703062e.1979.49.1123 
facilitado, confirman su interpretación. En un pasaje de los Anales de Cuauhtitlán (Lehmann 1938: 92-93), se informa que Topiltzin Quetzalcóatl murió en un año "l. acatl", permaneció por ocho días en el inframundo, y nació de nuevo para subir al trono en su aspecto de estrella matutina. Dispara sus rayos en determinados dias contra aquellos objetos que aparecen en las secciones del Borgia anotadas antes: en un día "1. caña" la estrella matutina, según los Anales, "dispara contra los reyes" (par. 155), representado en los códices por un asiento real cubierto con piel de tigre.

También dicen los Anales que Quetzalcóatl nació en un "año 1. caña" y que murió 52 años después. Un ciclo de 52 años está indicado en el lado reverso del monumento por medio del signo del año y una atadura. Sin embargo, no es seguro si estos datos son fechas calendáricas actuales o si tienen un sentido ritual-mitológico, y esta ambigüedad, así como el uso de diferentes calendarios en esas épocas, no permite establecer equivalencias en nuestro calendario (Davies 1977: 172).

Cualquiera de estas interpretaciones son tentativas, pero queda el hecho del temor que causaba la primera aparición del planeta Venus, por las consecuencias perniciosas para la humanidad. Esta circunstancia se expresa gráficamente no sólo en los tres códices del grupo Borgia, sino también, de modo similar, en el Códice de Dresden, por haberse difundido el concepto desde el Altiplano del centro de México hasta la región maya; y también se registra la influencia del planeta en la Estela de Guadalupe.

De paso mencionamos que en el Cerro de la Campana (o Peña Gorda), en la vecindad del pueblo de Guadalupe, se encuentran relieves "chichimecas" (seg. Krickeberg) ; el de mayor tamaño representa a Mixcoatl, deidad estelar conectada con Tlahuizcalpantecutli y padre de Topiltzin Quetzalcóatl. Seler copió los diseños en 1910 (GA 5:136, figura 8) y Krickeberg (1969: 109-113, figura 64) hizo unos comentarios al respecto de que allí existía un puesto militar chichimeco para cuidar la frontera contra las incursiones de los mixtecos en el siglo xmr.

\section{Conclusiones}

El primer estilo escultural plenamente desarrollado en la Mixteca Baja se denomina Nuiñe, y floreció entre 550-700 d. C. Se carac- 
teriza por la absorción de elementos iconográficos teotihuacanos y, sobre todo, de elementos zapotecos, así como por los glifos calendáricos derivados del sistema de Monte Albán. Las dos estelas descritas se encuentran en el centro de la región $\widetilde{N} u i \tilde{n} e$, pero indican mayor afinidad con las tres estelas de Xochicalco y las de Monte Albán que con los monumentos del estilo Ñuiñe (tabla I). Las estelas de Xochicalco, que forman un conjunto, datan de 600-700 d. C., según Pasztory (1973: 186), y después Xochicalco perdió su importancia como centro ceremonial, habiendo sido abandonado a principios del posclásico. Probablemente fueron artesanos emigrados quienes esculpieron las estelas de Guadalupe y Micaltepec hacia el final del epiclásico, y modificaron el estilo Nuiñe con elementos de Xochicalco y con otros del emergente estilo MixtecaPuebla. Es muy probable que la Lápida del Museo Pigorini también pertenezca a esta tradición, ya que está esculpida en ambos lados, rasgo desconocido en la escultura $\tilde{N}$ uiñe.

\section{NOTAS}

Las fotografías fueron tomadas por P. Tschol durante un viaje de Petlalcingo a Tehuacán, en compañía de Paul Kirchhoff. Ahora se puede llegar al pueblo de El Rosario Micaltepec por carretera no pavimentada, de aproximadamente $9 \mathrm{kms}$, que entronca con la carretera Puebla-Oaxaca a unos $13 \mathrm{kms}$, al sur de Acatlán.

Deseo expresar mi agradecimiento al doctor Peter Tschohl de la Universidad de Colonia y al doctor Erardo Weihmann por haberme facilitado sus fotografías, y también al doctor Heinrich Berlin por sus valiosas informaciones.

Ha sido presentado este trabajo en el "Simposio sobre problemas de la iconografía posclásica del arte de Mesoamérica", en el XLIII Congreso Internacional de Americanistas, celebrado en Vancouver, B. C., agosto 10-17, 1979. Por tratarse de un tema que no corresponde netamente al periodo posclásico no está incluido en las Actas del Congreso. 
TABLA I

DISTRIBUCION DE MOTIVOS SELECTIVOS

\begin{tabular}{llc} 
& \multicolumn{2}{c}{ ESTELAS } \\
ESIELAS DE MICALTEPEC Y GUADALUPE & MONTE DE XO- & TEOTI- \\
& ALBÁN CHICAL- & HUACAN
\end{tabular}

Motivos esculpidos en 2 lados del monumento

$\mathrm{x} \quad \mathrm{x} \quad \mathrm{x}$

Frente: Representativo (deidad de fertilidad vegetal)

$\begin{array}{ll}\mathrm{x} & \\ \mathrm{x} & \mathrm{x} \\ \mathrm{x} & \mathrm{x}\end{array}$

Reverso: Signos calendáricos

$\mathrm{x} \quad \mathrm{X} \quad \mathrm{x} \quad \mathrm{x}$

Signo del año trapezoidal entrelazado

\begin{tabular}{|c|c|c|}
\hline & & $\mathrm{x}$ \\
\hline $\mathrm{x}$ & & $x$ \\
\hline $\mathrm{X}$ & $\mathrm{x}$ & $\mathrm{x}$ \\
\hline & & $\mathbf{X}$ \\
\hline
\end{tabular}

Barra con remate agudo

$\mathrm{X}$

Numerales de discos perforados o semicuadrangulares $\mathrm{X} \quad \mathrm{X}$

Puntos (discos) debajo de la barra $\mathrm{x} \quad \mathrm{X} \quad \mathrm{X}$

Glifo en cartucho ovalado

$\mathrm{x} \quad \mathrm{x} \quad \mathrm{x}$

Glifo en cartucho con volutas laterales (Edentro de corte transversal de una vasija)

$\mathrm{X} \quad \mathrm{X} \quad \mathrm{x} \quad \mathrm{x}$




\section{BIBLIOGRAFIA}

Caso, Alfonso. "Sculpture and mural painting of Oaxaca." Handbook of Middle American Indians, vol. 3, pt. 2, 1965.

__. Los calendarios prehispánicos. México, 1967.

Davies, Nigel. The Toltecs until the fall of Tula. Norman, University of Oklahoma Press, 1977.

Jiménez Moreno, Wigberto. "Mesoamerica before the Toltecs", en Paddock, Ancient Oaxaca, 1966.

Krickeberg, Walter. Felsbilder Mexicos, II. Berlin, 1969.

Lehmann, Walter. "Die Geschichte der Königreiche von Culhuacan und Mexico" (Anales de Cuauhtitlan). Berlin, 1938.

Moser, Christopher L. Nuiñe writing and iconography of the Mixteca Baja. Vanderbilt University Publications in Anthropology, 19, Nashville, 1977.

Nrchorson, H. B. "An Aztec stone image of a fertility goddess." Baessler Archiv, 11. Berlin, 1964.

-__. "The significance of the 'looped cord' year symbol in Prehispanic Mexico: An hypothesis." Estudios de cultura náhuatl, 6. México, 1966.

Padpoc, John. "Oaxaca in ancient Mesoamerica", en Paddock, ed., Ancient Oaxaca. Stanford, 1966.

PaszTORY, Esther. "The Xochicalco stelae and a Middle Classic deity traid in Mesoamerica." Actas del XXIII Congreso Internacional de Historia del Arte, vol. 1. Granada, 1973.

SELER, Eduard. Gesammelte Abhandlungen, v. 2 y 5. Berlin, 1902/I5."

Thompson, J. Eric S. Maya hieroglyphic writing. Norman, 1950.

Tschoнl, Peter. Catálogo arqueológico y etnohistórico de Puebla-Tlaxcala. México, t. II, Ch-O. Colonia, 1977. 